TAPROBANICA, ISSN 1800-427X. April, 2011. Vol. 03, No. 01: pp. 1-4.

(C) Taprobanica Private Limited, Jl. Kuricang 18 Gd.9 No.47, Ciputat 15412, Tangerang, Indonesia.

\title{
EDITORIAL
}

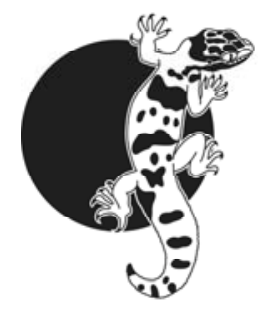

\section{A splitter's systematics of writing: \\ scientific writing and writing English are separate issues and this has implications}

Publishing is an essential component of scientific activity and an increasing number of well-known forces, but including also editors, press us to publish much (Werner, 1978). Recently, refinement of some of these forces coerces at least some of us to publish not merely in peer-reviewed journals but in those that are hardest to penetrate. My personal opinion that this is to the detriment of science (Werner, 2009) does not help. Publishing well is difficult. Here I try to analyze part of the difficulty and to conclude partial remedies.

The English language, and especially “American” (USAian), has become, or is becoming, the world's language of science. This is due to two successive historical situations: the size and geographical spread of the past British Empire, and the size and scientific productivity of the USA. Certainly, having a global language is advantageous for science. But that this language is English, is unfortunate. English is relatively difficult to learn, because there is no regular correspondence of spelling with pronunciation: "Now you read the red book that I read yesterday" - and this is a moderate example. This drawback is claimed to be offset by the famous richness of the English vocabulary. The latter is due in part to the language's dual origin. Additionally, linguistic richness goes hand in hand with national culture; not everybody has horsestallion-gelding-mare-foal-colt-filly. Piquantly, English has no word for the German verb gönnen, the opposite of grudge (=begrudge), i.e., feeling happy with somebody else's good fortune. Anyway, we are stuck with writing our papers in English.

Writing a scientific paper is a challenge, even after problems of contents have been settled. Help is available from many books (my favorite is by Trelease, 1969; but see comparative book review by Baker, 1969), guideline brochures, articles, websites of publishers and very detailed Instructions for Authors in some of the journals. In biology, many editors recommend, or even declare as adopted, the CBE (Council of Biology Editors) Style Manual (CBE Style Manual Committee, 1994) but few impose its simplest rules. Most of all this material radiates an attitude that scientific writing and writing English constitute one problem. In this spirit, a long scholarly editorial in an upper-class journal recently admonished, especially young Americans, to write more carefully (Heatwole, 2008). Rather than quote and repeat here that review of sloppy and faulty English in science papers (that is worth reading), I endeavor to base my argument below on additional points.

I consider scientific writing and writing English to be separate issues that sometimes clash. A notable example is, when $\mathrm{X}$ moved several times from A to B, the English teacher urges, "Don't monotonously repeat yourself. You have at your disposal walk, go, march, step, pace, stride, rush and others". In contrast, the scientific writing guide says, "If X did the same thing repeatedly, use the same verb. Keep the uniformity obvious, also in consideration of non-native readers.”

Most of the specific characteristics of scientific writing have nothing to do with English; they apply in any language. And some counter the ideals of elegant writing, in any language. They are intended to enhance communication, also for non-native readers. Foremost among these are plain language (as exemplified above); avoidance of verbosity (drop any phrase or word that does not add information; "very quickly" says no more than "quickly"); and avoidance of redundancy (said once is enough). These function in part through promoting brevity. Brevity in itself is good for the reader and therefore for the author and it alleviates the costs of publication.

Several rules of scientific writing are desirable everywhere although commonly taken lightly, but are absolutely necessary for the high-fidelity communication needed in science. These include clarity and lack of ambiguity. General words should be replaced with specific ones. Not "as he went" - either "when he went" or "because he went". Not "while he went" - either "when he went" or "although he went" (This one may vary among languages.). In this context I particularly negate the use of three punctuation marks. The slash or diagonal has too many meanings: A/B can mean (1) A divided by B. (2) A, which is part of B. (3) B, which is part of A. (4) A and B. (e.g., males and females). (5) A or B. (6) In "and/or" (prohibited but not 
imposed) it stands for A or B or both. I advocate minimizing the use of the hyphen because it so easily mutates from separating to connecting and vice versa. Worst is its common use in hybrid expressions of ranges. "Temperature varied from $10-15{ }^{\circ} \mathrm{C}$ " is prohibited (but rarely prevented) because it could be the beginning of "Temperature varied from $10-15{ }^{\circ} \mathrm{C}$ at night to $30-35{ }^{\circ} \mathrm{C}$ by day." Last, "bullets" to emphasize items in a list, come from advertizing. They are the uncivilized visual counterpart of raising the voice in vocal communication. Serial numbers would be more useful, can be referred to.

The need for sentence structure to facilitate understanding is much more acute in scientific writing than in other literature. Snake-sentences should be avoided even by herpetologists. Greater attention is required for the concept of parallelism. Not "There were 20 chairs in classroom A but in B only 18." Rather, "There were 20 chairs in classroom A but only 18 in B".

Another problem of English, that looms larger in scientific writing, is the capitalization of vernacular names of animals and plants. Many editors want these names to augment the scientific names, ostensibly because they could be more stable, or to attract readers to whom they are more acceptable. Normally such names are nouns in the English language and not capitalized (University of Chicago Press, 1969). "Have you tasted the fried Grey Mullet?" Looks as strange as "Have you fed the Cat". Until recently only (or mainly) the ornithologists have promoted their birds to capitalization, based on their global checklist. But for other groups there are no global lists and no general agreements. There is no reason to venerate (and capitalize) the English names given by enterprising Americans to exotic animals, the more so since many of these names violate the natural logic of vernacular names.

Some issues arise uniquely, or at least mainly, in scientific writing. The aspiration to clarity begets the (admittedly debated) rule to write in active voice, first person, and moreover for a single author (now almost extinct), in singular. This 'arrogance' is briefer, clearer, accepts responsibility. Abbreviations should be explained (once per paper!). Interestingly editors plead to minimize the use of abbreviations, while they urge to keep the text short. Some editors want them to be explained at first mention, charging the reader with remembering; other request a concentrated look-up table. Units of assorted measures must be metric. (Isn't it amusing how after the inch became metrically subdivided for precision purposes, now the geographical degrees are metrically subdivided. Of course, to the second it happened long ago.) Incidentally, sentences may not begin with an abbreviation or with digits.

The abstract is a major stumbling block. It should represent the contents, not define it. Thus "The average number of chairs per classroom was 18.5" and not "This project describes the furniture in classrooms" or "The number of chairs in classrooms was surveyed". It may not contain anything not represented in the main text. Opinions differ whether it, too, should be in active voice or maybe in passive voice.

In contrast, there exist pitfalls in writing English that do not really affect the fidelity of scientific communication. For some reason, we study at a university but in a department (e.g., of Zoology). If we ignorantly follow our logic and exchange the prepositions, everybody understands. If instead of "fewer readers" we write "less readers", everybody understands. If we, like most people, err in selecting "which" or "that" (see your larger dictionary), everybody understands. Boorish English in itself, although not exactly an honor, does not necessarily impede communication. For decades, the Journal of Zoology, London, has tolerated the faulty English of authors, as long as there occurred no ambiguity or other doubt as to meaning. Communicating in science and writing English are separate issues, and this generates some practical conclusions.

At another level, it is obviously important that authors would really say what they intend to say. (This differs from the issue whether what they intend to say is right or wrong.) Let me bring three examples of failure. The first is my own; the others are from much greater authors. (1) "The regenerated portion of each tail was distinguishable not only by radiography, but also by its ventral scales, which were smaller and paler than the original ones.” (Werner, 1967). Simple? But unfortunately, ventrally the regenerated part was darker, not paler, than the original, as shown in the accompanying photographs.

(2) "Critical reexamination of Gadow's theory of the composition of vertebrae from four pairs of arcualia is inapplicable to tetrapods...” (Williams, 1959). This was the opening sentence of the abstract! The author obviously intended to say, not that the reexamination was inapplicable, but that it showed that the theory was inapplicable (as shown in the text).

(3) "A recent example of an uncertain object of a verb is: 'Males consumed more prey than females.' This implies that males consumed females to a greater extent than males consumed prey." (see 
Heatwole, 2008). But the commenting author obviously intended to say, "This implies that males consumed females to a lesser extent than males consumed prey."

One might well ask, so, whence all this sloppiness that has been lamented by Heatwole (2008) and indicated here? While a general review and analysis of sloppiness are outside my competence and Taprobanica's scope, in this case I can suggest a hypothetical source: University professors, the people who educate heads of state, school teachers, and scientists. Based on my experience in Israel and the USA, and on evidence from Germany, I dare say that they too often refrain from correcting their students. Saving their own time is only a fringe benefit. The real purpose is to be attractive to the students, because nowadays research students are manpower producing papers for the teacher's resume. They say, "No need to harass them with technicalities. They will learn them when needed." They don't consider that sloppiness is sloppiness and in some situations (the roads are famous) sloppiness is lethal.

So what are we to do about all this? I see two practical conclusions. First, if we accept that scientific writing and writing English are separate issues, we should separate their teaching. Scientific writing should be taught everywhere in the local language, including all examples and exercises. This would make the teaching, including learning, more effective, and would lead to better understanding and acceptance of the logic. It would also increase the number of potential teachers. Separately, it would be nice to have the teaching of English improved (expanded and deepened) and this can be done (or guided) by teachers who are ignorant of science. The students should be able to merge the two inputs and would gain much more.

Second, it is always prudent and productive to show our manuscript to a friend before we ejaculate it to an editor. But such preliminary peer review is doubly important when we suspect that the editor knows us and respects us and thus might be misguided to economize and take the reviewing lightly.

Third, if we could revive the historical ethics that a research student's project is the student's project and is published by the student (the teacher is paid to teach the student how), we would restrain the incentive for the teacher to attract students. Students would still be wanted, to pass the flame to them, but would be educated without such fear of hurting their feelings.

\section{Acknowledgement}

I thank Harold Heatwole for constructive and encouraging reading of the manuscript.

\section{Literature cited}

Baker, S., 1969. Book reviews: Clarity. Science, 166: 365-366.

CBE Style Manual Committee, 1994. Scientific style and format: The CBE manual for authors, editors, and publishers. 6th ed. Style Manual Committee, Council of Biology Editors, Cambridge and New York, Cambridge University Press: 825.

Heatwole, H., 2008. Editorial—A plea for scholarly writing. Integrative and Comparative Biology, 48: 159163.

Trelease, S. F., 1969. How to write scientific and technical papers. Cambridge, Mass., M.I.T. Press: 39.

University of Chicago Press, 1969. A manual of style. $12^{\text {th }}$ ed. Chicago and London, The University of Chicago Press.

Werner, Y. L., 1967. Regeneration of specialized scales in tails of Teratoscincus (Reptilia: Gekkonidae). Senckenbergiana. Biologia, 48:117-124.

Werner, Y. L., 1978. How editors catalyze the publication explosion, in: Scientific information transfer: the editor's role (Proceedings of $1^{\text {st }}$ International Conference of Scientific Editors, Jerusalem, Israel, 1977) ed. M. Balaban. Dordrecht, Holland \& Boston, Mass., USA, D. Reidel Publ. Co., 113-121.

Werner, Y. L., 2009. The Aspiration to be Good is Bad: The 'impact factor' hurts both science and society. The International Journal of Science in Society, 1: 99-106. 
Williams, E. E., 1959. Gadow's arcualia and the development of tetrapod vertebrae. Quarterly Review of Biology, 34: 1-32.

Yehudah L. Werner

Sectional Editor: Taprobanica, the journal of Asian Biodiversity

March 04 ${ }^{\text {th }}, 2011$

The Alexander Silberman Institute of Life Sciences,

The Hebrew University of Jerusalem,

91904 Jerusalem,

ISRAEL

and

Museum of Zoology (Museum für Tierkunde),

Senckenberg Dresden,

A. B. Meyer Building, Königsbrücker Landstraße 159,

D-01109 Dresden,

GERMANY

From Volume 3: Number 1, Taprobanica - The Journal of Asian Biodiversity (ISSN: 1800-427X) is published by Taprobanica Private Limited - Sri Lanka, which is registered as a private company limited, incorporated under the Companies Act No. 7 of the Democratic Socialist Republic of Sri Lanka (company registration no. PV 77205) as of 15th February 2011. The trade mark for the journal is illustrated here (slightly changed from the previous mark published).

This trade mark is registered under the Intellectual Property Act No. 36 of 2003 as an individual trade mark of A. A. Thasun Amarasinghe (trade mark registration no. LK/T/1/164048).

The editor-in-chief (Taprobanica journal) \& Chairman (Taprobanica Pvt. Ltd.)

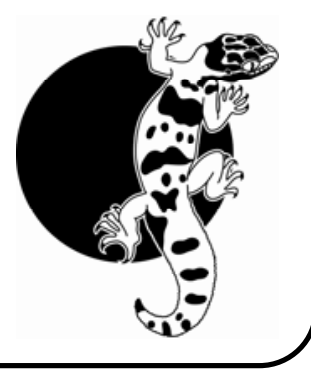

